\title{
La sociedad riverense vista a través de la fotografía entre los años 1920 y 1930
}

\section{A sociedade riverense estudada a través da fotografia entre os anos 1920 y}

\author{
1930
}

\section{The riverense society stydy by photographies from the years 1920 y 1930}

\author{
Raquel Rodriguez ${ }^{1}$ \\ Victoria Méndez ${ }^{2}$
}

\begin{abstract}
Resumo
Como parte da equipe multidisciplinar em Estudos de Fronteira (EMEFRO) do CeRP del Norte, em parceria com o Museu do Patrimonio Regional, se opto pelo estudo da sociedade riverense abordando a temática da fotografia. Este projeto de pesquisa se centra no estudo da sociedade na cidade de Rivera através de analises da fotografia familiar entre 1920 y 1930. Com esta pesquisa se procura conhecer como era percebida a sensibilidade da época. A traves da fotografia se procura identificar as classes sociais, a organização familiar, os papéis conforme os gêneros y os elementos que formavam a identidade da sociedade; tendo em conta o contexto no qual estava inserta a cidade de Rivera. Atraves deste estudo foi possível obter a informação para alcançar interpretar este espaço de fronteira. $\mathrm{O}$ interesse de este trabalho e fornecer relevância a esta região, que até o momento tem sido pouco estudada e mostrando características próprias que permanecem esquecidas.
\end{abstract}

Palavras chave: Fotografia, Fronteira, Identidade, Região, Sociedade.

\section{Resumen}

Como parte del Equipo Multidisciplinario en Estudios de Frontera (EMEFRO) del CeRP del Norte, en acuerdo con el Museo del Patrimonio Regional, se optó por el estudio de la sociedad riverense abordando la temática de la fotografía. Este proyecto de investigación se centra en el estudio de la sociedad en la ciudad de Rivera a través del análisis de la fotografía familiar entre 1920 y 1930. Con esta investigación se busca conocer cómo se percibía la sensibilidad de la época. A través de la fotografía se busca identificar las clases sociales, la organización familiar, los roles según los géneros y los elementos que componían la identidad de la sociedad; teniendo en cuenta el contexto en el que se encontraba inserta la ciudad de Rivera. A través de este estudio se estará obteniendo la información para lograr interpretar este espacio de frontera. El interés de este trabajo es proporcionar relevancia a esta región, que hasta el momento ha sido poco estudiada y mostrando aquellas características propias que han permanecido olvidadas.

Palabras clave: Fotografía, Frontera, Identidad, Región, Sociedad.

\section{Abstract}

\footnotetext{
${ }^{1}$ Centro Regional de Profesores del Norte. Rivera, Uruguai. noely.1712@gmail.com

${ }^{2}$ Centro Regional de Profesores del Norte. Rivera, Uruguai.victoriamn2013@gmail.com
} 

e-ISSN 2016/Atual: 2525-7870 | e-ISSN 2015/2016: 2447-018X

As parto $f$ the Equipe multidisciplinaria em Estudos de Fronteira (emefro) do CeRP del norte, in partnership with the Museu do Patrimonio Regional, choosed the study of the riverense society using the photographic theme.

This review was centered on the study of the societyon the Rivera City, besides the familiar photographic analisis between 1920 and 1930.With this research, we demand ask how was seeing the sensibility of the time. Throught the photographies was demand identify the social class, the familiar organization, the papers about genre and the elements who forme the society; taking into account, wich the city was uncertain. The interest of this work is giving information to catch up the interpretation of the frontier. The interest of this researcj Is to provide relevance to this region, who wasn't' being studied and showing that own characters who will be forgett.

Key Words: Photographic, Frontier, Identity, Region, Society

\section{1- Introducción}

En este artículo se busca conocer la sociedad en la ciudad de Rivera entre los años 1920 y 1930 a través del análisis de la fotografía familiar. Antes de abocarnos al estudio de esta región en específico, es relevante destacar que las sociedades latinoamericanas son dependientes en todas las áreas (económicas, políticas, sociales) de las grandes metrópolis europeas y norteamericanas. El desarrollo urbano en un principio surge en las zonas en donde el capitalismo colonial encontró ventajas logrando extraer metales preciosos; pero ya en el siglo XVIII la sociedad urbana emergente tiene un carácter predominantemente comercial y burgués, por lo que la urbanización se trasladara específicamente en los países de la banda atlántica sudamericana, a las zonas de puerto, como por ejemplo Buenos Aires y Montevideo (QUIJANO, 1976). Esa urbanización explica la relación de dependencia entre la región latinoamericana y la metrópoli.

El desarrollo urbanístico al dar preferencia a las zonas favorables para el comercio, pasa a ignorar otras zonas en donde se produce también una ocupación poblacional del territorio. La forma de ignorar estas zonas tendra una gran magnitud, que no solo sera evidente en lo que refiere al comercio y la economía sino también en los registros documentales que muy poco mencionan esas regiones. Un ejemplo de las mencionadas zonas ignoradas es la región fronteriza de Rivera y Santana do Livramento, en donde no existió un desarrollo urbanístico pleno hasta la segunda mitad del siglo xx, pero si existía una población instalada, y es esa población que fue objeto de análisis, centrando la atención en lo que refiere a la sociedad y como esta puede ser vista a través de los registros fotográficos. En el caso específico de esta investigación, la imposición cultural es evidente en las fotografías familiares (BENJAMIN, 1936)

\section{2- Revisión de literatura}


Al ser una zona fronteriza el objeto de esta investigación debemos tener en cuenta ciertos conceptos para entender la particularidad de esta región, en comparación con el resto del país. Estos conceptos son: territorio, región y frontera.

Según Santos (1996) estas categorías de análisis no se pueden analizar de forma separada, debido a que el movimiento del territorio está íntimamente unido al movimiento de construcción, desconstrucción y reconstrucción de nuevas regiones. Para Hasbaert (2007), el territorio siempre envuelve una dimensión simbólica, cultural, a través de una identidad territorial atribuida por los grupos sociales como forma de control simbólico sobre el espacio donde viven, y una dimensión más concreta de carácter político disciplinar, una apropiación y ordenación del espacio como forma de dominio y disciplinamiento de los individuos. Este mismo autor también expresa que región es por lo tanto una dimensión real de la vivencia de los individuos y de los grupos, y es a partir de ella que se crea una base territorial.

La frontera según Areces (1999) es definida como un espacio de interrelaciones dinámicas entre sociedades distintas, en donde el Estado está aún en proceso de estructuración de sus instituciones y su sociedad. El Estado no llega al control total de ese espacio debido a su permeabilidad. Este espacio altamente permeable en diversas áreas (económicas, sociales, culturales), se desarrolla más allá de los límites políticamente establecidos. La frontera no es un hecho inmutable en el tiempo sino que puede cambiar y está siempre en proceso de construcción. Dentro del concepto de frontera encontramos una construcción histórico- social de la población que ocupa ese espacio, y por el otro lado, sociedades que compiten por el predominio dentro de ese espacio. Según Frederick Jackson Turner (1987), la frontera no es considerada como una línea divisoria, sino como un espacio en donde se van formando los elementos constitutivos de la identidad de una determinada sociedad.

Teniendo claro estos conceptos y considerando que la zona de frontera analizada no se encuadra dentro del modelo urbanístico descripto anteriormente, de igual modo se puede decir que "toda nueva organización del espacio será una forma de expresar un nuevo modo de poblamiento, unas nuevas estructuras económicas y sociales, unas nuevas formas de poder, un nuevo sistema de valores. Se desprende por consiguiente que a través del análisis de las huellas dejadas en el espacio por una sociedad de pueden construir sus perfiles y sus formas de organización" (ARECES, p.3). En esta investigación se buscó a través de la fotografía, encontrar las huellas de la sociedad riverense de principios de siglo xx.

Como nuestra principal fuente para recabar información fue la fotografía, cabe realizar una breve reseña sobre la importancia de la misma para construir el relato histórico. Según Legarreta (2008) la fotografía comienza a ser utilizada como una herramienta auxiliar de la 
historia práctica en el siglo XIX, en donde predominaba la corriente ideológica positivista. Era considerada como un instrumento más fiel e imparcial de la reproducción de la sociedad, y poseía un carácter archivístico.

En la década del 30 del siglo XX, Walter Benjamín (1936) menciona el carácter revolucionario de la fotografía como documento histórico por su capacidad de cortar y guardar un preciso fragmento de la realidad, proporcionando una visión parcial de la época histórica y el espacio geográfico donde se desarrolló. A pesar de la gran utilidad de la fotografía, no se puede caer en el error de considerar esa imagen como un reflejo exacto de la época, ya que las épocas históricas no son lo bastante homogéneas para que sean representadas en una sola fotografía. Sin embargo se debe destacar que es una interesante y rica mirada del pasado sobre una determinada época.

En la actualidad, la fotografía es considerada una fuente histórica más para construir el relato histórico, sin embargo

\begin{abstract}
Son relativamente pocos los historiadores que consultan los archivos fotográficos comparados con los que trabajan en los depósitos de documentos manuscritos o impresos. [...] Cuando utilizan imágenes los historiadores suelen tratarlas como simples ilustraciones, reproduciéndolas en su libro sin el menor comentario. En los casos en que las imágenes se analizar en el texto, su testimonio suele utilizarse para ilustrar las conclusiones a las que el autor ya ha llegado por otros medios y no para dar nuevas respuestas o para plantear nuevas cuestiones (BURKE 2005, p 33).
\end{abstract}

Lo afirmado por Burke se puede deber a la falta de herramientas metodológicas para interpretar imágenes y sacar de ellas toda la información que nos puede brindar, y esto se debe a que la formación académica sigue basándose en la lectura y el manejo de documentos escritos.

La fotografía según Moreira (1993) posee una naturaleza polisémica ya que esta puede tener diferentes lecturas de acuerdo a su receptor. Lo que se ve en la fotografía dependerá de quien lo mira. Estas necesitan tener una descripción para ser útil al trabajo científico.

Debido a que el trabajo investigativo se centró en retratos familiares, es relevante destacar las características de estas imágenes. Según Bourdieu (2003) la fotografía tiene el objetivo de eternizar los momentos de la vida familiar, y reforzar la integración del grupo familiar, produciendo un sentimiento de pertenencia y de unidad. Se destaca como relevante este tipo de fotografía debido a que es una plasmación de la genealogía familiar, brindando información de los miembros que la componen a las futuras generaciones.

Según Ortiz (2006) en la sociedad a finales del siglo XIX, se fotografiaban preferentemente adultos, ya que los niños eran considerados menos importantes. Ya entrado el 
siglo xx, la fotografía se encontraba más generalizada, y comienzan a aparecer fotografías de niños en fotografías especiales como la primera comunión.

Otro tipo de fotografía familiar en el siglo XIX y principios del XX es el retrato de los cadáveres de infantes (ORTIZ, 2006). Estos poseen una postura yacente, sentados o incluso siendo cargados por sus padres. El objetivo de tomar dicha fotografía es similar al anterior mencionado, ya que servirá como recuerdo del breve pasaje de este niño en el núcleo familiar.

En las fotografías de esta época investigada podemos observar que sus miembros adoptan una postura frontal e hierática en el momento del registro, trasmitiendo la importancia del acto que encerraba tomarse una fotografía. Esta constituía una verdadera ceremonia la cual implicaba preparar el escenario, la vestimenta y la concurrencia hacia el estudio fotográfico. Los retratos de familia tenían un patrón común que subrayaba la jerarquía en el grupo. Siempre el padre y la madre, o en todo caso los mayores, están en el centro de la fotografía, rodeados de hijos, hijas, nietos, yernos y nueras. Esto refleja una sociedad patriarcal que dominaba en el siglo XIX y principios del siglo XX (ORTIZ, 2006).

Como ya aclaramos en el presente artículo nos encontramos con que sobre la sociedad y la fotografía existe gran cantidad de información escrita, sin embargo nos encontramos aún muy lejos de poseer bibliografía sobre la sociedad en general del departamento de Rivera y sobre la fotografía como herramienta histórica para el estudio de dicha sociedad.

\section{3- Método}

Para cumplir con el objetivo general de conocer y analizar la sociedad de Rivera entre los años 1920 y 1930 y con los objetivos específicos de analizar la organización familiar teniendo en cuenta la posición que cada miembro de la familia ocupaba en el momento de sacarse una fotografía; determinar la clase social a la que pertenecían teniendo como herramienta las vestimentas que utilizaban en las diferentes fotografías y conocer las costumbres que caracterizaban la sociedad riverense teniendo en cuenta los momentos en que era realizado el acto de sacarse una fotografía; la fuente histórica utilizada y analizada es la fotografía familiar como anteriormente se describe, como primer paso se buscaron esas fotografías en el Museo del Patrimonio Regional.

Para lograr interpretar lo que en estas fotos se observa como herramienta para la recolección de datos se utiliza la entrevista. Las mismas se realizan a familiares de quienes aparecen en las fotos tomadas como muestra. Las preguntas realizadas en las entrevistas buscan entender como era el entorno familiar de la época, qué rol cumplía cada miembro de la familia teniendo en cuenta el género, quien era el jefe de familia, si lo característico eran las 

e-ISSN 2016/Atual: 2525-7870 | e-ISSN 2015/2016: 2447-018X

familias patriarcales, como era visto y vivido el momento de sacarse una foto, los detalles de ese momento y que lugar ocupaba cada miembro de la familia en esa foto.

En base a las respuestas obtenidas de los entrevistados se analizan e interpretan las diferentes fotos encontradas de la época investigada. De esta forma se logra interpretar y conocer la sociedad riverense, sus costumbres, las diferentes clases sociales, como se percibía la sensibilidad en esa época.

\section{4- Resultados}

Para lograr analizar e interpretar las diferentes fotografías se procedió a entrevistar a descendientes de los individuos que aparecen en las fotos, además de personas las cuales sus familiares vivieron en Rivera en el lapso de tiempo investigado.

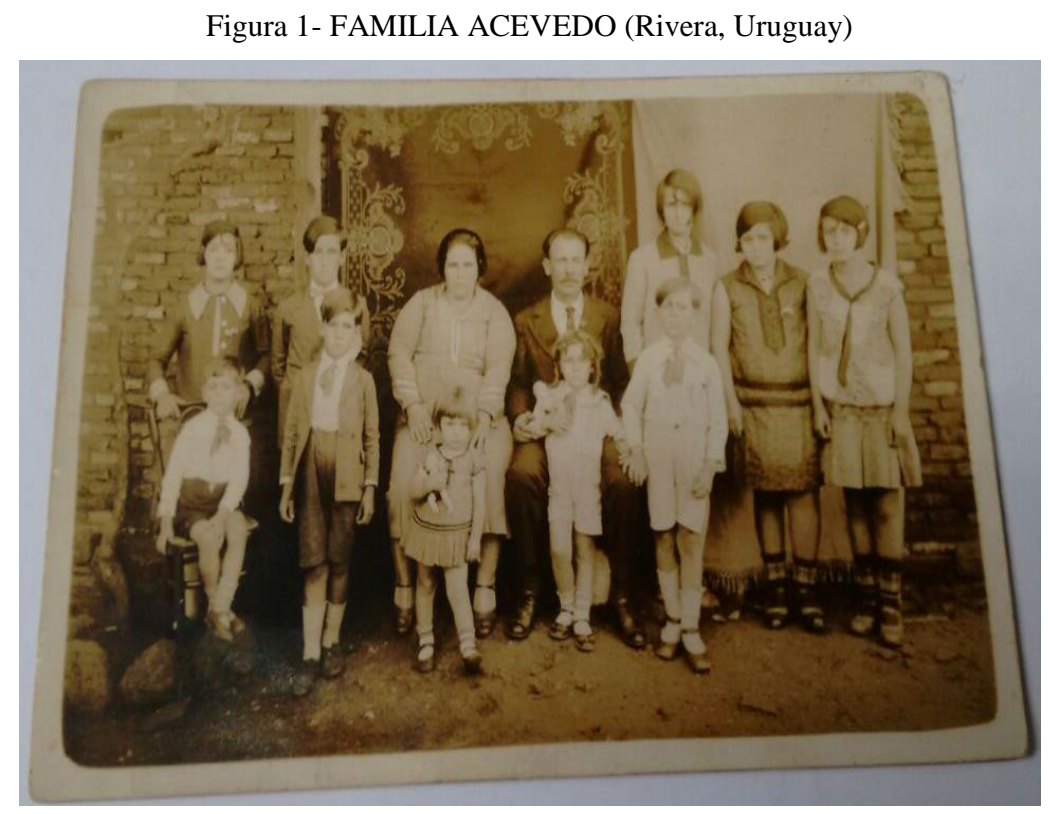

Fuente: Museo del Patrimonio Regional- IDRivera 1920-1930 aprox.

El padre de familia era quien trabajaba en una actividad asalariada, fuese esta actividad la de empleado público, como en el caso del abuelo de la Sra. Rosa Ferrón, quien era policía rural, otros trabajaban la tierra, podían ser propietarios de chacras en donde plantaban y criaban animales que luego serian comercializados. Los demás miembros de la familia se distribuían de la siguiente manera: la madre, se encargaba de la educación y cuidado de los hijos, de ayudar al padre de familia en las tareas de la tierra si era necesario, 
además de mantener la limpieza de la casa, confeccionar ropas y preparar los alimentos para todos los miembros de la familia. ${ }^{3}$

Los demás integrantes de la familia; si eran varones, ayudaban al padre en la actividad en la tierra, que aunque muchas veces no se trataba de una gran producción, por lo general poseían una producción doméstica que era la base del sustento familiar; si eran del género femenino, se dedicaban a ayudar a la madre y a servir a los hombres de la casa, sin importar si esos hombres fueran de menor edad que ellas. Esto se pudo observar que sucedía tanto en familias ricas como pobres.

Figura 2- FAMILIA FERRÓN MARQUEZ (Rivera- Uruguay) 1930 aprox.

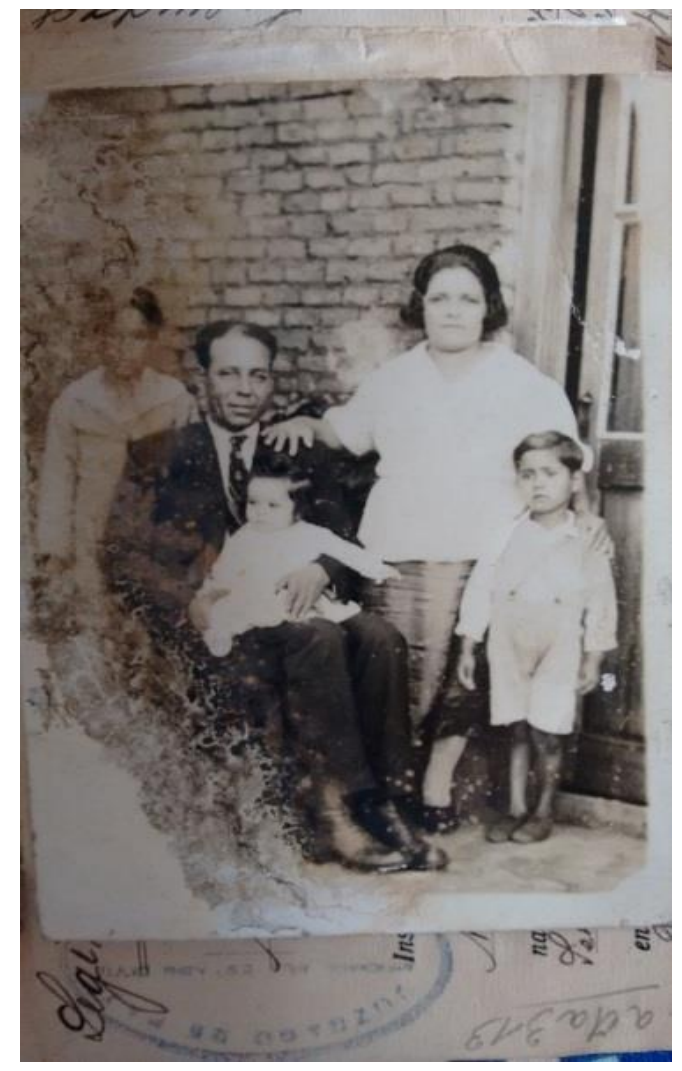

Fuente: Cedida gentilmente por Ferrón, Rosa

Otra característica de estas familias era que se reunían a diario a la hora del almuerzo, ocasión que no era permitido estar ausente. Como momentos especiales de reunión familiar estaban los cumpleaños, casamientos y las fiestas tradicionales (navidad y fin de año). Y eran estas ocasiones en que por lo general se sacaban fotos, la razón muchas veces se debía a que era cuando la familia se reunía en su totalidad, pero además porque como lo expresó una de

\footnotetext{
${ }^{3}$ Entrevista a la Sra. Ana Olga Alvez (2016)
} 

e-ISSN 2016/Atual: 2525-7870 | e-ISSN 2015/2016: 2447-018X

las entrevistadas, la Sra. Ana Olga Alvez, era cuando se podían enviar esas fotos, por intermedio de familiares que habían concurrido a la reunión, a otros familiares que no habían podido estar presentes. De esta manera se lograba mantener la unión y el contacto familiar, algo que era muy importante para la sociedad de ese momento.

Figura 3- FAMILIA DE OLIVERA Uruguay1920 aprox.

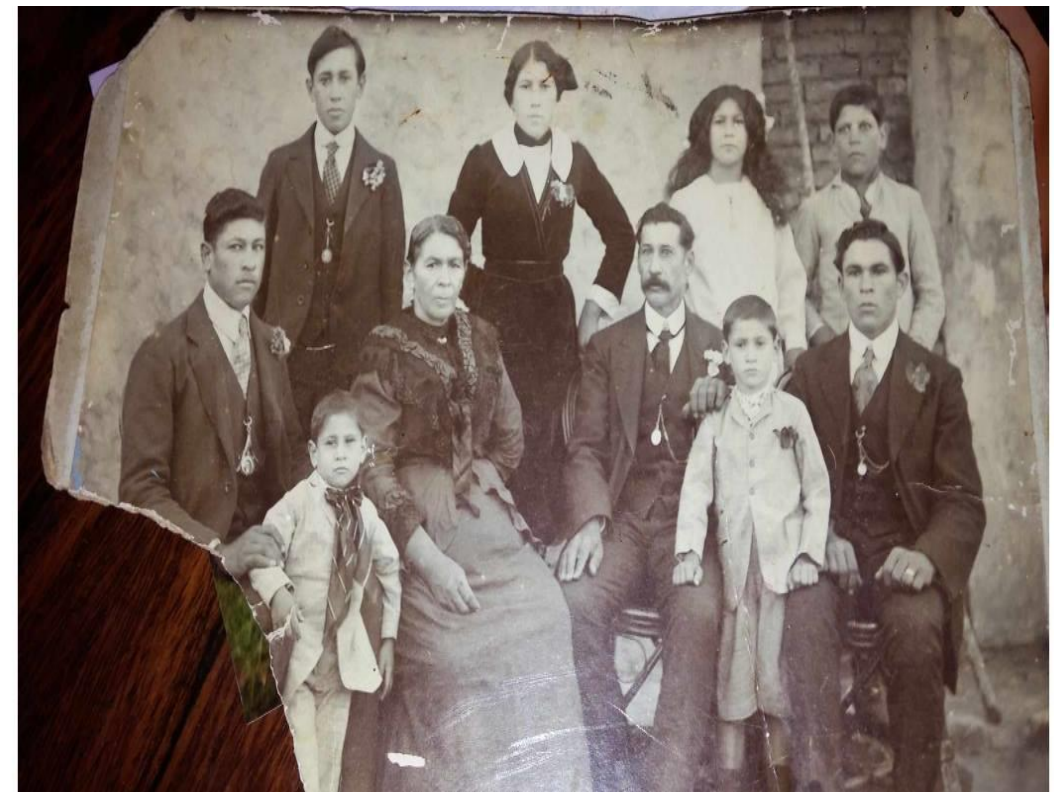

Fuente: cedida gentilmente por Silveira, Santiago

Sacarse fotos era un evento muy importante, y más para aquellas familias pobres donde era muy difícil y costosa esa práctica. Por la importancia de la misma, había toda una preparación previa; primeramente se marcaba la fecha del evento, debido a que se debía contratar al fotógrafo que por lo general concurría al domicilio de quien contrataba sus servicios.

Posterior a esto se debía preparar la vestimenta que se utilizaría. En el caso de las familias pobres por lo general era la madre de familia quien confeccionaba las prendas, ya en el caso de quienes poseían otros recursos económicos podían contratar quien confeccionará las vestimentas o solicitarlas por encargue que fuesen traídas de Montevideo o de alguna ciudad de Brasil, ya que al ser este un espacio de frontera había también comunicación con el estado brasileño de Rio Grande.

Con respecto a la confección de vestimentas, la madre de familia solía imitar los diseños utilizados por las familias de elite, diseños inspirados en la moda europea. En esto se 
ve reflejado la imposición cultural y la dependencia que existe en la sociedad latinoamericana con respecto a las grandes metrópolis (QUIJANO, 1976).

Lo que queda evidente es que las prendas que usarían serian las mejores que tuvieran. El padre de familia usaría traje siempre, sin importar si fuese nuevo o ya muy viejo, pero eso era señal de autoridad frente a la familia. ${ }^{4}$

Una vez que se lograba esto se establecían los lugares que cada miembro de la familia debía ocupar en la foto. El padre de familia por lo general estaba sentado y ocupaba la parte central de la foto, ya que era el jefe de familia debía ocupar este lugar considerado de privilegio y de honor. Luego lo acompañaría la madre de familia, quien podía estar sentada o parada al lado del padre de familia, era el lugar secundario en la fotografía. Después se pasaba a establecer el lugar de los hijos, los más pequeños irían en la parte de adelante, dándole también un mejor lugar si eran varones y más atrás colocados a la espalda del padre de familia o en los laterales, irían los hijos más grandes como en el ejemplo de la fotografía de la familia Acevedo.

\section{5- Discusión}

Con la información obtenida podemos describir que en su gran mayoría las familias eran patriarcales en la sociedad riverense entre 1920 y 1930, o sea que el jefe de familia era un hombre. Lo que demuestran las diferentes fotografías analizadas es que de acuerdo al estatus social de la familia dependerá la cantidad de fotos que saquen, o sea que las familias más ricas tendrán un mayor acervo de fotografías familiares en comparación a aquellas familias más pobres. Muchas veces este evento se realizaba por una única vez, esto lo podemos afirmar fundándonos en las manifestaciones de los entrevistados.

También de este estatus social dependerán las vestimentas que utilicen cada uno de los integrantes de la familia. En la fotografía de la familia Ferrón Márquez vemos claramente que son ropas muy sencillas y según su nieta eran confeccionadas por su abuela o eran regalos de familiares que vivían en Montevideo. Lo contrario podemos observar en la fotografía de la familia Olivera en donde se percibe la calidad de las vestimentas y los relojes que llevan puestos los hombres que aparecen en la foto.

De igual modo no podemos dejar de considerar que la fotografía es solo un recorte de un momento específico del pasado, no se debe por lo tanto generalizar esta fuente histórica, ya que nos proporciona una visión parcial de la época histórica investigada (Benjamín, 1936).

\footnotetext{
${ }^{4}$ Entrevista a la Sra. Rosa Ferrón (2016)
} 

e-ISSN 2016/Atual: 2525-7870 | e-ISSN 2015/2016: 2447-018X

Otro elemento a destacar son las clases sociales que se observa a través de las fotos analizadas.

Según Lenin, Las clases son grandes grupos de hombres que se diferencian entre sí por el lugar que ocupan en un sistema de producción social históricamente determinado, por las relaciones en que se encuentran con respecto a los medios de producción (relaciones que las leyes refrendan y formulan en gran parte), por el papel que desempeñan en la organización social del trabajo, y, consiguientemente, por el modo y la proporción en que perciben la parte de la riqueza social de que disponen (Lenin, 1961, p, 479,).

Basándonos en la definición de Lenin, podemos afirmar que no todas las familias poseían el mismo acceso a las riquezas, y esto es lo que se observa en sus vestimentas. Quienes pertenecen a una clase social alta vestían mejores ropas y más accesorios de lujo, ya las familias pertenecientes a las clases más bajas o sea con menores riquezas, careceran de esas vestimentas lujosas y de accesorios.

Pero no dependera de este estatus social todo el ritual previo a sacarse una foto; tantos las familias ricas como las pobres consideraban este evento algo de gran importancia y por lo tanto había una gran preparación. Otro elemento importante que se ha podido observar es que tampoco dependía de la clase social el lugar que ocupaba el hombre en el núcleo familiar, para todas las clases sociales este género era el que tenía la autoridad en la familia, y esto se observaba claramente en el lugar central que ocupaba en el momento de sacarse la foto, dándonos la clara idea de una sociedad en donde este género era el que dominaba e imponía sus reglas y costumbres a la familia. Esto se puede explicar a través de la ideología patriarcal que predominaba en la mitad del siglo XX y que continuo predominando por casi todo el siglo $\mathrm{XX}$.

Una ideología es un sistema coherente de creencias que orientan a las personas hacia una manera concreta de entender y valorar el mundo; proporciona una base para la evaluación de conductas y otros fenómenos sociales; y sugiere respuestas de comportamiento adecuadas (LAGARDE, 1997).

Es este el caso de las ideologías patriarcales que no solo construyen las diferencias entre hombres y mujeres, sino que las construyen de manera que la inferioridad de las mujeres es entendida como biológicamente inherente o natural. Aunque las diversas ideologías patriarcales construyen las diferencias entre los sexos de manera distinta, en realidad este tipo de ideologías sólo varían en el grado en que legitiman la desventaja femenina y en el número de personas que comparten un consenso sobre ellas. Las ideologías patriarcales no sólo afectan a las mujeres al ubicarlas en un plano de inferioridad en la mayoría de los ámbitos de 
la vida, sino que restringen y limitan también a los hombres, a pesar de su estatus de privilegio. En efecto, al asignar a las mujeres un conjunto de características, comportamientos y roles propios de su sexo, los hombres quedan obligados a prescindir de estos roles, comportamientos y características y a tensar al máximo sus diferencias con ellas (LAGARDE, 1997). Esto se evidencia de forma muy precisa y clara en las fotos analizadas al tener ese lugar central el hombre en el momento de registrarse fotográficamente un momento familiar.

\section{Referências}

ARECES. R (sin fecha). Regiones y fronteras. Apuntes desde la historia, Revista Andes (N.10). pp 1-10.

BURKE, P. Visto y no visto. El uso de la imagen como documento histórico. Ed. de bolsillo. España, 2005.

CLEMENTE. E y otros. Territorio, regiao e fronteira. Estudios urbanos y regionales V13, (N.2) pp 101-116, 2012.

HAESBAERT, R. O mito da desterritorializção: do fim dos territórios á multiterritorialidade. Rio de Janeiro, Brasil: Bertrand Brasil, 2007.

LAGARDE, M (1997). Identidad de Género y Derechos Humanos: La construcción de las humanas, en Caminando Hacia la Igualdad Real. Manual en Modulos. Programa Mujer, Justicia y Género. Recuperado en http://centreantigona.uab.es/docs/articulos/Feminismo, \%20g\%C3\%A9nero\%20y\%20patriarca do.\%20Alda\%20Facio.pdf Recuperado: 9 setiembre 2016.

LEGARRETA, J, La fotografía como fuente de análisis de los procesos migratorios: metodología, conceptualización y crítica en la historia de la emigración vasca a Uruguay (XIX, XX). Salamanca, España: Graficas Varona S.A, 2008.

LENIN Una gran iniciativa en Harnecker. M. (1979) Clases sociales y lucha de clases. Venezuela: Akar, 1961.

MOREIRA. M . Retratos de familia: leitura da fotografia histórica. Sao Paulo, Brasil: EdUSP, 1993.

QUIJANO. A (1968). Dependencia, cambio social y urbanización en Latinoamérica. Recuperado en http://biblioteca.clacso.edu.ar/gsdl/collect/clacso/index/assoc/D9635.dir/eje1-1.pdf.

ORTIZ, G "Una lectura antropológica de la fotografía familiar", Editorial Archiviana, Madrid, 2006. 

e-ISSN 2016/Atual: 2525-7870 | e-ISSN 2015/2016: 2447-018X

TURNER, F, J. (1920): The Frontier in American History, New York: Henry Holt and Company. El significado de la frontera en la historia americana, Secuencia $N^{\circ}$ 7, enero, Abril 1987.

RODRIGUEZ. F. Retratos de familia, una manera de hacer historia: Imágenes visuales del entramado social. http://www.banrepcultural.org/node/32426. Recuperado: 9 de setiembre 2016. 